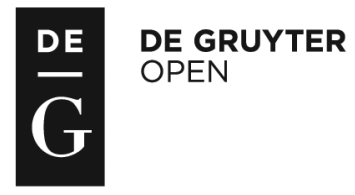

Administration, vol. 64, no. 2 (2016), pp. 109-136

doi: 10.1515/admin-2016-0018

\title{
Towards a more person-centred home care service: A study of the preferences of older adults and home care workers
}

\author{
Catherine Dempsey \\ Health Service Executive \\ Charles Normand \\ School of Medicine, Trinity College Dublin \\ Virpi Timonen \\ School of Social Work and Social Policy, Trinity College Dublin
}

\begin{abstract}
The purpose of this study was to investigate the views of older home care recipients on the care that they receive and the preferences of the home help staff to work more flexible times, in order to provide a more person-centred service for the older person. A mixed-methods design was used, incorporating both qualitative and quantitative research methods. The qualitative phase involved five focus groups (total participants: $n=23$ ), to gain information on the recipients' views on the home help received and how the service may become more person-centred. The quantitative phase involved sending postal questionnaires to Health Service Executive (HSE) home help employees $(n=202)$ and to home help employees from a voluntary home help agency in Dublin South West $(n=147)$. The findings from the qualitative phase of the
\end{abstract}


research highlighted that the recipients were mainly satisfied with the service received but would like more communication with home help managers, and to be consulted regarding their care to allow for a more person-centred service. Companionship was also identified as a need for the older person. Data from the quantitative analysis indicated that home help employees, particularly in the HSE, are willing to work outside current contracted hours; for example, 8 p.m. to midnight midweek, or on Sunday evenings. Therefore, the future possibility of recruiting HSE home help staff to work more flexible hours needs to be considered to allow for a more person-centred home help service.

Keywords: Home help, home care, older person, outsourcing, person-centred care

\section{Introduction}

Long-term care policy in Ireland conforms to the general pattern of policy recommendation across most developed welfare states, namely that older people should be supported to remain in their own homes for as long as possible (Department of Health and Children, 2001; 2012; Genet et al., 2011). This has resulted in an increase in demand for home care services (Genet et al., 2011; King et al., 2012; Larsson et al., 2013). The allocation of the appropriate home care to meet the needs of the older person in the community is vital in achieving this policy objective (Skaperdas et al., 2010). Home care can be defined as help with personal care, which includes bathing and getting dressed, in addition to help with domestic duties (Karlsson et al., 2013; Rostgaard, 2012). Traditionally, home help in Ireland has focused on assistance with instrumental activities of daily living such as cleaning, shopping and cooking (Timonen et al., 2012).

Initially, home help services were seen as an ad hoc service provided by neighbours to the older person in the community (National Council on Ageing and Older People \& Department of Health and Children, 1998). Home help was originally provided by local health boards, and was not a statutory service. Therefore, home help was only provided to those who had no family support, or to those who had no assistance from the voluntary home help agencies (Department of Health, 1972). Thus, unlike other social services, the home help service was susceptible to reductions in funding by the government (Lundstrom \& McKeown, 1994; Timonen et al., 2012). Voluntary home help agencies were established by the religious orders in Ireland, and have been funded by the state since 1953 (Timonen \& Doyle, 2007). Prior to 
2000, employees had not been paid a salary, but since then carers and management in this area have been paid a wage, and several are entitled to social benefits. The role of the religious orders in the management of the voluntary home help agencies is now minimal (Timonen \& Doyle, 2007).

The first for-profit provider of home care was established in Ireland in the late 1980s (Lundstrom \& McKeown, 1994; Timonen \& Doyle, 2007). Today, several private providers advertise home care on a $24-$ hour basis, and offer a dual service of providing both personal care and domestic duties (Timonen \& Doyle, 2007). This flexibility has contributed to competition at the regional level between private agencies, voluntary agencies and the Health Service Executive (HSE) home help services. The contracting out of home help services has increased globally in the last decade, and often the decision to privatise care is influenced by political agendas, economic policy and cultural change (Dybbroe, 2008; Stolt \& Winbald, 2009).

The Home Care Package (HCP) system, first introduced in 2005 in Ireland, allowed a percentage of home care to be outsourced by the HSE to profit-making private agencies (Department of Health and Children, 2005). This system aimed to facilitate the efficient discharge of patients from hospitals into primary care, by complementing existing services in addition to preventing inappropriate admissions to hospital (Department of Health and Children, 2009; Doyle \& Timonen, 2007). Although there has been an increase in the amount of hours outsourced to private providers for home care, there has been very little development in standardisation and regulation of the home care sector at the national level. Standards and regulation have largely been confined to service-level agreements between the HSE and provider organisations (Timonen \& Doyle, 2008; Timonen et al., 2012). O'Shea \& Connolly (2012, p. 1,368) characterise the introduction of HCPs as a measure to support 'weak and fragmented community-based services' characterised by 'provision determined more by the needs of the provider than the needs of the older person and their carers'.

In Europe the population over eighty years of age will grow from 3 per cent in the year 2000 to 6.4 per cent in 2030 (Boeckxstaens \& De Graff, 2011, p. 371). In an attempt to meet the needs of the ageing population living at home, the HSE refocused home help services from only delivering general domestic duties to assisting also the older person with activities of daily living, such as personal care (HSE, 2011). Doniol-Shaw \& Lada (2011, p. 35) note that redesigning the 
home help service to provide personal care has been a positive step, but has resulted in care becoming 'compartmentalized', which 'contradicts the very nature of home care work'.

In 2014 the HSE provided 10.3 million hours of home help for personal care and essential household duties. This was in line with the targeted level of service identified in the 2015 service plan and, as a result, maintained the service provision of 2012 and 2013 (HSE, 2014; 2015). Approximately 47,200 people nationally were in receipt of home help services on 31 December 2014 (HSE, 2015). This service was mostly provided by HSE home help employees and by the voluntary home care agencies mainly based in Dublin, Wicklow and Clare, in addition to service provision from private for-profit agencies in some areas (HSE, 2015). The first two (HSE and voluntary agencies) are responsible for providing the bulk of home care services in Ireland, hence the focus on them in this article.

The existing model of HSE home help in Ireland is, in many cases, restricted to providing a service from 8 a.m. to 8 p.m., Monday to Friday, a pattern that does not reflect the fact that care needs occur around the clock. The limitations of the service can occur in certain areas as a result of budget constraints and the hours for which home helps are contracted to work (Labour Court, 2013; O'Shea \& Connolly, 2012, p. 1,368). Other issues relating to the governance of home helps and the reporting of adverse incidents outside of regular working hours have led to caution in implementing the service after 6 p.m. and at weekends by home help managers (INMO, 2015).

\section{Literature review}

King et al. (2012, p. 365) state that in the current circumstances of an ageing population, demand for home care services increases. Furthermore, Normand (2012) states that demands for home care are often higher than demands for hospital care when there is an increase in the older population. The demand for twilight and night-time services and the apparent lack of flexibility by the HSE home help service to provide care outside daytime hours have been contributing factors in the expansion of private home care providers (Timonen \& Doyle, 2007, p. 6).

Flexibility in home care has been introduced into some public health care systems in Europe to allow more negotiation between the carer and the home help in responding to the older person's needs (Rostgaard, 2012). Breitholtz et al. (2013, p. 6) state that older people 
'are aware of their own vulnerability and dependence but still want to be independent'. The involvement of patients and their families are important elements to achieving a person-centred system and improving care services (Barello et al., 2012). Rostgaard (2012) discusses the introduction of flexibility in the home help service in Denmark that allowed service users to negotiate change of times and tasks with home helps, without risking the loss of hours that had been allocated. This was an attempt to counteract the previous system, which was referred to as the 'tyranny of minutes' by politicians. In the Irish context the Health Information and Quality Authority (HIQA) states that person-centred care has the service user at the core of the service, which is provided by 'actively involving them in the provision of care' (HIQA, 2012, p. 19).

Another relevant consideration for the background of our study is the provision of financial incentives for staff to allow more flexibility in the public home help service. The definition of an incentive is 'any factor financial or non-financial' that contributes to choosing one option over another and that provides motivation (Flodgren et al., 2011 , p. 3). Howes $(2008$, p. 46) carried out a survey in 2008 in the US among 2,260 care workers to investigate the impact of wages and other benefits on home care workers and their willingness to remain in their jobs. The results indicated that commitment to their clients was the main reason they commenced working as home care workers and that the flexibility of the work was the second most important reason for remaining in their job. A literature review carried out by Genet et al. (2011) on home care in Europe identified only four studies that dealt with pay and conditions of workers. Rostgaard (2012) identified that there was a high turnover of employees in home care because of poor wages in the sector, and that working as a home help was seen as a lowstatus job in some countries. This can lead to difficulty in the retention of employees, which results in a lack of continuity within the service. A study by Chester et al. (2014) suggested that the provision of training for employees assisted agencies in retaining staff. King et al. (2012) states that the availability of trained and skilled staff is critical to delivering a high-quality service in home care, which is preferable to the option of residential care for the older person.

Against this background in policy and literature, the aims of this study were to, first, explore the satisfaction and preferences of home help recipients within the current model of care and, second, to probe the willingness of home help workers to respond to one aspect of these preferences, namely more flexible service delivery. 


\section{Research methods}

An exploratory, sequential mixed-method approach was adopted for this study to investigate the care recipients' views on their home care service, in addition to identifying the preferences of the home help staff, with a focus on their willingness to adopt more flexible working times. The relationships between research questions and elements of research design are summarised in Table 1.

Table 1: Relating the design to the research questions

Research questions Research design

1. What elements of home care provision need to be prioritised from the service users' perspective?

1. Focus groups with older people in receipt of home care from the HSE and the voluntary home help service.

2. What would motivate home help staff to work outside 8 a.m. to 8 p.m. contracted hours to allow a more flexible home care service?

3. What are the areas of the HSE home help service that need to change to meet the older person's needs?
2. Postal questionnaires issued to home help staff employed by the HSE and a voluntary agency.

3. Integrative analysis of both the qualitative focus group data and quantitative survey data.

In the mixed-methods approach adopted here, the qualitative component was developed to gain an insight into the preferences of the older care recipients regarding the home care service they received, and, on the basis of this, the quantitative component was employed to survey employees to explore one aspect of possible change towards more person-centred care, namely the incentives that would encourage them to work more flexible hours. The main steps in the research process are outlined in Figure 1.

\section{Qualitative phase}

The first research question in this study refers to the elements of home help that need to be prioritised from the service users' perspective. This was addressed by the use of focus groups with older people who were in receipt of the service. The focus group design yielded data on participants' views on the home help service they receive. The older 


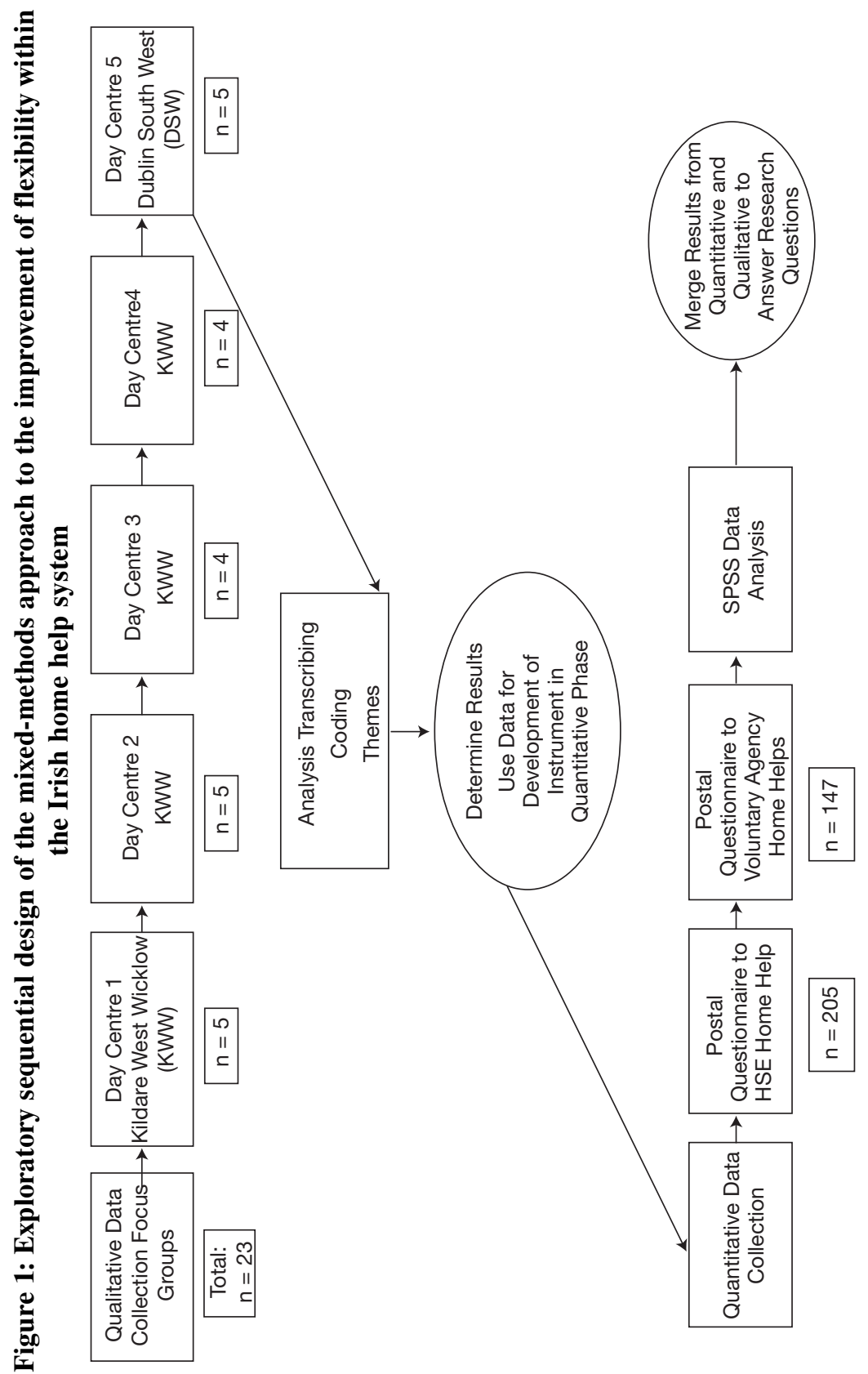


people were encouraged to identify characteristics that they felt were needed to provide a more person-centred service.

Four HSE day centres selected for the proposed research were situated in Kildare West Wicklow (KWW), along with one day centre in Dublin South West (DSW). The sites were reasonably typical in terms of the mix in the provider landscape in that the majority of services were provided by the HSE, with some involvement from voluntary and for-profit sectors. Five focus groups (with four to five participants in each) were then conducted in the five selected day centres. Participants were selected for the qualitative part of the research based on the following inclusion criteria:

- those aged sixty-five years and over;

- those in receipt of home help or HCPs, including clients in receipt of the HSE home help service, in addition to clients in receipt of home care from voluntary agencies and private providers;

- those attending one of the four HSE day centres in KWW or the day centre managed by a voluntary agency in DSW.

Participants were excluded from the focus groups based on the following exclusion criteria:

- those aged under sixty-five years of age who were in receipt of home help or HCP;

- those who were diagnosed as terminally ill;

- those who had any form of dementia.

The main characteristics of focus group participants are summarised in Table 2.

The total number of care recipients in the groups was twenty-three. A third of the participants were men, which was important for investigating home care from both the male and female perspectives. There was a selection of people from both urban and rural areas, and more than half of the participants lived alone. The rest of the care recipients lived either with family or in housing which catered for independent living. Fourteen of the participants were in receipt of home help from the HSE or a not-for-profit voluntary agency. Two older people were in receipt of HCP from for-profit home care agencies, and five of the participants were in receipt of both home help and a HCP. 
Table 2: Focus group participants

\begin{tabular}{llc}
\hline & Description of participant & $\begin{array}{c}\text { Number of } \\
\text { participants }\end{array}$ \\
\hline Gender & Male & 8 \\
Residential area & Female & 15 \\
& Urban & 15 \\
Household composition & Rural & 8 \\
& Living alone & 14 \\
& Sheltered accommodation & 4 \\
Type of care received & Living with family & 5 \\
& Home help & 14 \\
& HCP & 2 \\
& Home help and HCP & 5 \\
& Private care & 2 \\
\hline
\end{tabular}

Participants identified to take part in the focus groups were issued an information pack relating to the proposed study, which included consent forms and a letter of invitation from the area manager of the HSE DSW area. The lead author met with each participant a week prior to signing the consent form, which allowed a 'cooling off' period in the event that they did not want to participate in the research. A formal schedule of questions was not developed prior to commencing the pilot (in order to allow maximum openness to diverse views); however, prompts and probes were used to generate discussion in the event that participants were reluctant to talk about their experience.

Limitations of the focus groups included:

- dementia care recipients were excluded;

- the majority of participants did not have high dependency needs;

- the focus groups had an unequal gender balance (one-third male participants only);

- the lead researcher's experience in home care could have influenced the direction of the focus groups;

- the lead researcher had worked in the HSE home help service as a home help manager, which may have influenced the participants in becoming involved.

Open coding was used to analyse the data from the focus groups, which involved labelling segments of the transcripts and subsequently 'comparing, conceptualizing and categorising data' (Strauss \& Corbin, 
1990, p. 61). 'Bottom up' codes emerged from the transcripts to identify categories, and relationships between the codes were developed by comparing categories, a process known as axial coding. Finally, selective coding was used to identify the core themes in the data collected. Theoretical saturation was reached when no new themes emerged (Glaser \& Strauss, 1967).

\section{Findings from the qualitative phase}

Following examination of the transcripts and listening repeatedly to the recordings of the five focus groups, the following key themes were identified:

- satisfaction with the service;

- centrality of the carer for the successful delivery of home care;

- lack of communication with home help managers;

- need for companionship.

These themes are outlined and discussed in turn; all respondent names are pseudonyms.

\section{Satisfaction with the service}

Most of the participants expressed satisfaction with the service in relation to issues such as the time of the call, the duration of the call and the flexibility of the service. Some felt that the call was instrumental in allowing them to remain at home, particularly if the carer called to assist them to bed or to check in at night with them. Some of the participants who did not receive a call in the evening expressed a desire to have such a service, as they felt it provided security.

Over half of the care recipients lived alone and received a daily call from a home help, which they felt was very beneficial to them and provided them with the security to know that someone was calling every morning. However, a small number of the participants expressed dissatisfaction with the time allocated to them, thus indicating that the duration of the call was a critical factor in their satisfaction with the home care service. Some of the care recipients were annoyed that they only had a small allocation of hours and felt that because of their age they were entitled to more care:

I think it's ridiculous for a person of my age to have an hour of home help... it's really an insult for an hour once a week. (Sarah) 
Many of the care recipients admired how their home helps organised their workloads, as they felt that home help workers had a number of tasks to perform in a short period of time:

My home help has a system when she comes in she says... 'What do you want to eat today?'... but when she is cooking the dinner she is making my bed... sweeping the floor... she is very organised... she is only there for the hour so she knows she can't dilly dally. (Joseph)

Examples of personal care ranged from help with dressing or a shower and the provision of breakfast. However, in many instances the respondent indicated that $\mathrm{s} / \mathrm{he}$ had washed and dressed before the carer came into the home even though the service had been initially allocated for this purpose. Some of the care recipients were proud that they could perform these duties, and could help the carer in addition to exerting their independence:

I can get myself up and dressed but I can't hoover. She makes my bed but I can dress myself. (Kathleen)

I can get myself dressed too. (Joan)

Some of the participants with higher dependency needs relied on the carer to assist them to get up in the morning and to get back to bed at night. Usually in KWW the night-time or evening calls were provided by a private agency and, according to the participants, the time of this call was crucial to assisting the participant to live in their own home. For the participants who were in receipt of a HCP and needed a higher level of care, this was provided by private for-profit agencies in KWW and the care recipients felt that this service allowed them the independence to attend a day centre:

My carer calls shortly after 8 on a Monday morning because I am gone at 8.50 a.m. [to attend the day centre] and she comes back in at 5 p.m.... that's every day. I get into bed at 5.30 or $5.45 \ldots$ I can't get in myself... I can sit on the bed but it's very hard to get into bed. (Helen)

When asked if Helen had chosen early evening to return to bed, she assured the group: 
I looked for that time... it's early. I always go down at that time of the evening. I am lying in the bed watching telly and I as soon be in my bed than sitting up. (Helen)

Satisfaction from the service users' perspective in all the focus groups was therefore linked to the flexibility of the duration and time of the call in addition to the tasks provided by the service.

\section{The importance of the carer}

Many of the participants felt that carer characteristics were central to their satisfaction with the service. A number of older people in the focus groups expressed concern for their carer because of the risks involved for carers undertaking duties with reduced hours. Some wanted to carry out tasks to alleviate what they perceived as carer burden and to demonstrate their ability to carry out instrumental activities of daily living such as preparing food:

Mine can be a bit rushed because she goes to other people to shower... I cook my own breakfast before she comes in. I cook the porridge the night before so I can put it in the microwave. (Kathleen)

Continuity of the carer was considered a standard requirement by the care recipients and many of them voiced their opinions strongly on this issue during the focus groups:

I haven't had a home help on and off since Christmas... she left because apparently she was going to do other work as a carer in the HSE so that was the last I saw of her... then I got a relief, a great worker but she got sick and then that's the last I saw of her... she started in the day centre for two hours, 12 to 2 p.m., but I thought she would get sick because she was so particular in my house ... I then got someone for... two weeks and I now have someone else until she is ready to get back. (Anne)

Conversely, other participants had the same home help for a number of years and spoke about their carer with great affection. They also took pride in being able to perform certain duties themselves to minimise the carer's workload, as they were concerned for their wellbeing. 


\section{Communication}

Many of the participants were annoyed about the lack of communication from home help managers, and felt that this was a security issue as they may not know who would replace a home help who was on leave:

The one thing I am not happy with is that when they are not coming they are supposed to ring and tell you who is coming instead and they never do... so you don't know who is coming to the door... I often go to the door and say, 'Who are you?'... we are old people on our own and we should know... they don't seem to care. (Joseph)

Similarly, several of the care recipients were unsure if they would get relief or not. Many of them were surprised to learn in the focus groups that some people did get relief, which indicated that frequently people were not clear from the beginning about the way the service is delivered:

When [carers] were away for long periods I wasn't able to get any word about it... I phoned up but didn't get much response... the fact of being left there and not being able to communicate with anyone. (Eileen)

The participants felt that there was a greater need for clarity for the service users regarding the allocation of relief and the duties that the home help can provide. When probed further, the care recipients in all of the groups identified that they would like to see the introduction of some form of feedback that would allow them to contribute to the further development of the home help service:

They could ring and say how do you feel today?... but they might be afraid you would complain. (Eileen)

The involvement of patients and their families are vital elements to achieving a person-centred system and in improving healthcare services (Barello et al., 2012). According to Gruman et al. (2010), the cost of not engaging with patients is a lower standard of care, poor health outcomes and wasted resources. 


\section{Companionship}

Almost all of the participants in the focus groups identified that companionship was a key need in the older person's life, regardless of whether the participants were in a rural or urban area. In many instances they looked forward to the home help calling as they may not see anyone else during the week:

She only has half an hour to take out the ashes but she still talks to me... the doctor said it's for the company, Mary, not for what they do for you. (Mary)

All of the participants enjoyed going to the day centres and saw it as a social event that provided companionship. Many of the care recipients lived alone and identified the day centre as an important feature in their weekly routine:

I have my shower in here [day centre]... it's only once a week... I would be lost only for them here... It's great. They are fantastic here. (Mary)

Some participants were allocated an evening call from either home help or HCP. They felt that this call was central to providing companionship because it meant that the home help would 'sit and chat', as s/he was less busy in the evening. Many of the care recipients expressed the weekend as being a lonely time and felt that the call at the weekend was important to have someone to talk to:

I hate Sunday... if [carer] is away, the other lady comes in... I needed someone at the weekend. (Anne)

They don't have to do much but my thing is there is someone there to talk to. The company is so important. (Michael)

It was also apparent from the conversations that the participants valued the contact of their family and enjoyed the routine of family calling to help with certain tasks such as bringing them shopping or assisting them to bed.

The focus groups illustrated that the care recipients were generally satisfied with the service they received, and that the carer was a key component to their perception of the service. They also identified the need for more communication with the managers of the service, and 
expressed a desire to become more involved in the planning of their own care regarding the flexibility of tasks and time of the call. Companionship was a key theme that emerged from the qualitative data phase, and the carer was a vital part of fulfilling this need, particularly in the evenings and at weekends. Several of the participants felt that Sunday was a lonely day and that they would benefit from a call at this time. Those who had an evening or nighttime call were satisfied with it and felt that the carer had more time to talk to them at these times.

\section{Quantitative phase}

The results from the first phase of the research were relevant to the second research question, which focused, in line with some of the preferences identified in the focus groups, on home help employees' preferences to work certain hours and on incentives that would motivate staff to work more flexible hours. Data collected in the qualitative phase of the research study assisted in the development of the questionnaires, which were sent out to home help personnel. These included questions that related to their availability to work outside currently contracted hours and specified financial incentives that might encourage them to work such hours.

The target population for the quantitative part of the research were the 349 home help personnel employed by the HSE in KWW and the voluntary not-for-profit agencies in DSW. A total of 196 questionnaires were returned, 110 from HSE staff and 86 from the voluntary agencies, which indicated a total response rate of 56 per cent (Table 3).

Filter questions were avoided to prevent omissions, and short, closed questions were used to avoid 'respondent fatigue' (Bryman, 2004, p. 133). Questions relating to financial incentives were calculated on the current salary scale of home help employees within the HSE and the voluntary home help sector. HSE home helps are paid a starting salary of $€ 12$ per hour, which increases annually until the highest payment of $€ 15$ per hour is reached. Employees also benefit from mileage allowance and receive training. Employees in the voluntary home care agency who are included in this study are paid $€ 12.50$ per hour, increasing to $€ 13.75$ after one year. They are not in receipt of a mileage allowance and are expected to pay for their own training in care of the older person, although mandatory induction and training in patient moving and handling are provided to ensure the 
implementation of the Safety, Health and Welfare at Work Act, 2005. The questionnaire was designed to be user-friendly by creating a onepage document formatted with questions on the back and front of the page. Home help personnel from an existing database were used to identify participants to take part in the study. Home helps were excluded from the survey based on the following criteria:

- HSE employees who had been directly line-managed by the lead researcher in the past;

- home helps employed by private for-profit agencies in KWW/DSW.

Table 3: Breakdown of the participants involved in the quantitative data-collection phase

\begin{tabular}{lccccc}
\hline $\begin{array}{l}\text { Number of postal } \\
\begin{array}{l}\text { questionnaires } \\
\text { distributed }\end{array}\end{array}$ & Male & Female & $\begin{array}{c}\text { Total } \\
\text { sent }\end{array}$ & $\begin{array}{c}\text { Total no. of } \\
\text { questionnaires } \\
\text { received }\end{array}$ & $\begin{array}{c}\% \text { received } \\
\text { (response } \\
\text { rate) }\end{array}$ \\
\hline HSE staff & 0 & 202 & 202 & 110 & 54 \\
Voluntary agency staff & 5 & 142 & 147 & 86 & 58 \\
Total questionnaires & 5 & 344 & 349 & 196 & 56 \\
\hline
\end{tabular}

The choice of quantitative data analysis in this study was determined by the secondary research question, which sought to measure the home help employees' availability to work more flexible hours and the factors that would incentivise them to work these hours. Therefore, the computer-based analysis programme SPSS (version 22) was selected to process a bivariate analysis. A bivariate analysis examines the relationship between variables (Bryman, 2004). Frequency tests and cross-tabulation tables were chosen by the researcher to perform the analysis on the data received from the questionnaires. The chisquare test was used to determine whether there was a statistically significant difference between the response frequencies for staff from the HSE and those from voluntary agencies. The results of the analysis were displayed using column and bar charts. All percentages in the charts were displayed to the nearest decimal point.

One limitation of the survey was that Question 9, which asked the respondent to choose additional tasks that they would perform if allocated an extra fifteen minutes, may have yielded more meaningful results if worded differently. Some of the respondents ticked two of the tasks (HSE $n=2,11.3$ per cent; voluntary $n=10,12$ per cent). However, this resulted in the researcher being unclear on the two tasks 
that had been chosen by the home help employees. The survey should have indicated to the respondents more clearly to tick just one of the boxes on the question. Also, home help employees from the voluntary agency in this study were available for weekends and provided calls until 9 p.m., unlike the HSE home help employees, a consideration that might have influenced some of the responses.

\section{Quantitative results}

\section{Home help preferences to work outside contracted hours midweek}

The following analysis relates to Question 3 on the questionnaire, which investigated home helps' preferences for working outside the 8 a.m. to 8 p.m. contracted hours. This question was based on the care recipients' discussion in the focus groups on the need for an evening call to assist in getting ready for bed and for the security of a carer to check on them, particularly if they are living alone.

\section{Figure 2: Home helps' preference for working 8 p.m. until midnight} midweek (\%)

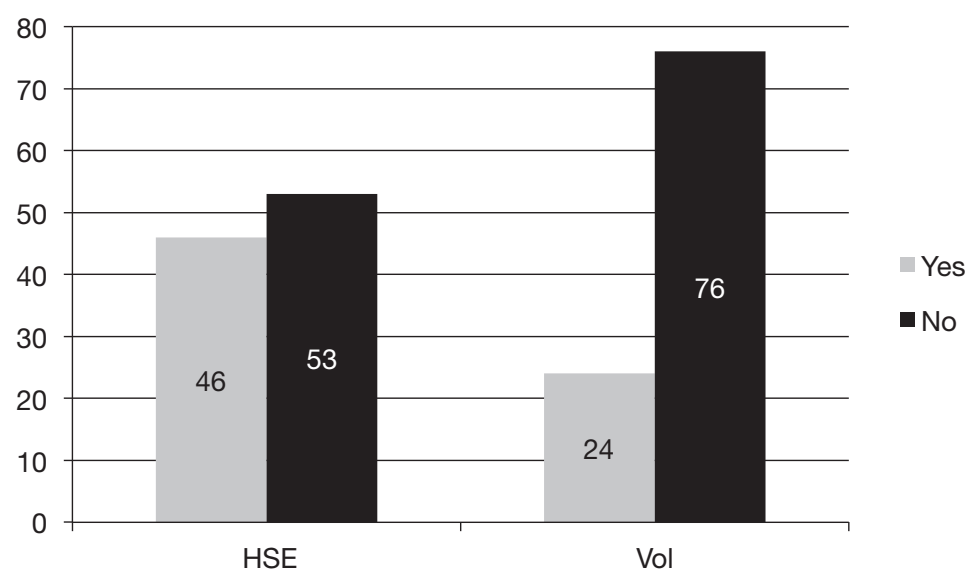

A total of 196 employees (HSE $n=110,100$ per cent; voluntary $n=$ 86, 100 per cent) responded to the question highlighted in Figure 2. Just under half of the participants from the HSE ( $n=50,46.3$ per cent) indicated that they would be willing to work Monday to Friday from 8 p.m. to midnight. However, a smaller proportion of participants from the voluntary agency $(n=21,24.4$ per cent) indicated that they would work the hours. A small majority of HSE home helps $(n=58,52.7$ per 
cent) and a large majority of home helps from the voluntary agency $(\mathrm{n}=65,75.6$ per cent) indicated that they would not be prepared to work Monday to Friday, 8 p.m. to midnight. The difference in the frequency of viewpoints between the two groups is significant $\left[\chi^{2}(1, \mathrm{n}=194)=9.876, \mathrm{p}=0.002\right]$

No pay rate was specified on this question, but the data were consistent with further analysis carried out to determine if the employees would work these hours when the pay rate was visible on the questionnaire. In this case a higher percentage of employees indicated that they would work 8 p.m. to midnight (Figure 3).

Figure 3: Home helps' preference to work for the standard pay rate from 8 p.m. until midnight (\%)

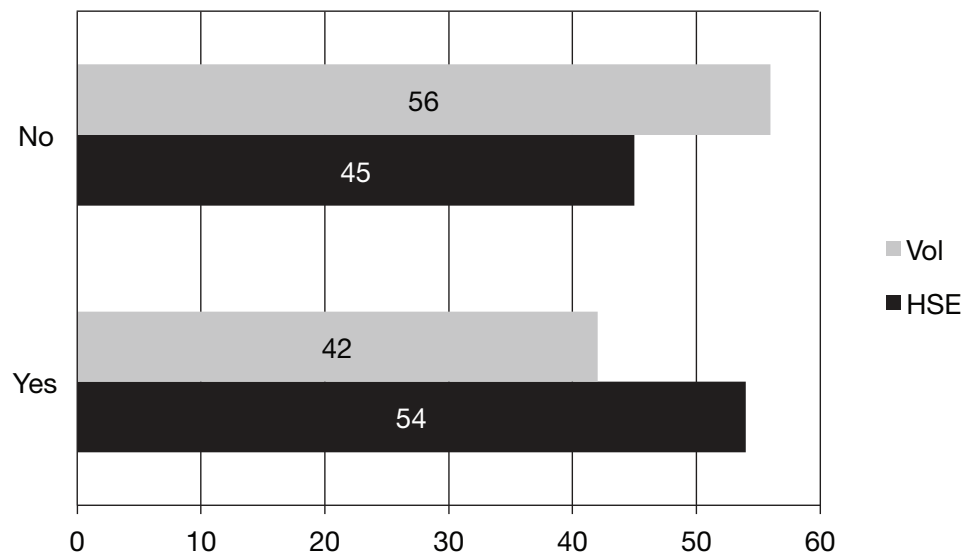

Over half of the respondents working as HSE employees (HSE $\mathrm{n}=60,54.5$ per cent; voluntary $\mathrm{n}=36,42.4$ per cent) indicated that they would work from 8 p.m. to midnight for the standard pay rate of $€ 17.50$ per hour, and a smaller percentage of voluntary agency employees said that they would work for their current rate of $€ 16$ per hour. A higher number of voluntary agency staff than HSE staff indicated that they would not work the hours for the same pay rate (HSE $n=50,45.5$ per cent; voluntary $n=48,56.5$ per cent), but the difference in frequency of viewpoints is not significant $\left[\chi^{2}(2, \mathrm{n}=195)=3.9, \mathrm{p}=0.142\right]$.

Employees were more willing to work the hours of 8 p.m. to midnight than the midnight to $8 \mathrm{a} . \mathrm{m}$. shift for the standard pay rate of $€ 19$ for HSE staff and $€ 17.50$ for voluntary agency staff per hour (Figures 3 and 4). 
Figure 4: Home helps' preference to work from midnight to 8 a.m. for the standard pay rate $(\%)$

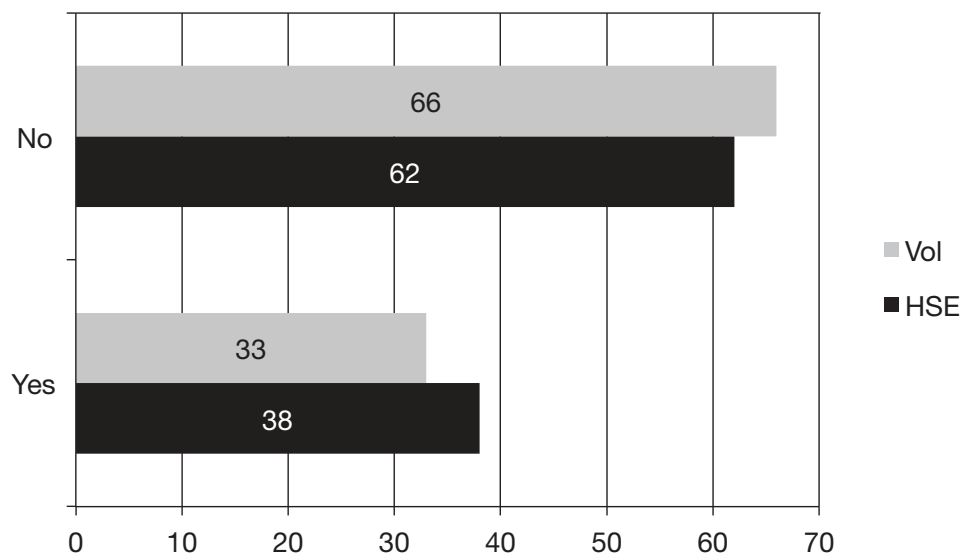

A little over one-third of HSE employees $(n=42,38.2$ per cent) indicated that they were willing to work from midnight to 8 a.m. for $€ 19$ per hour. A similar proportion of voluntary agency home help employees ( $n=29,33.7$ per cent) were willing to work the hours for $€ 17.50$ per hour. The difference in frequency of the views between the two groups is not statistically significant $\left[\chi^{2}(1, n=196)=0.416\right.$, $\mathrm{p}=0.519]$.

Figure 5 refers to Question 12, which asked HSE home helps if they would work on a Saturday night from midnight until 8 a.m. in the

Figure 5: Home helps' preference for working a Saturday night from midnight to 8 a.m. for $€ 30$ or $€ 23$ per hour (\%)

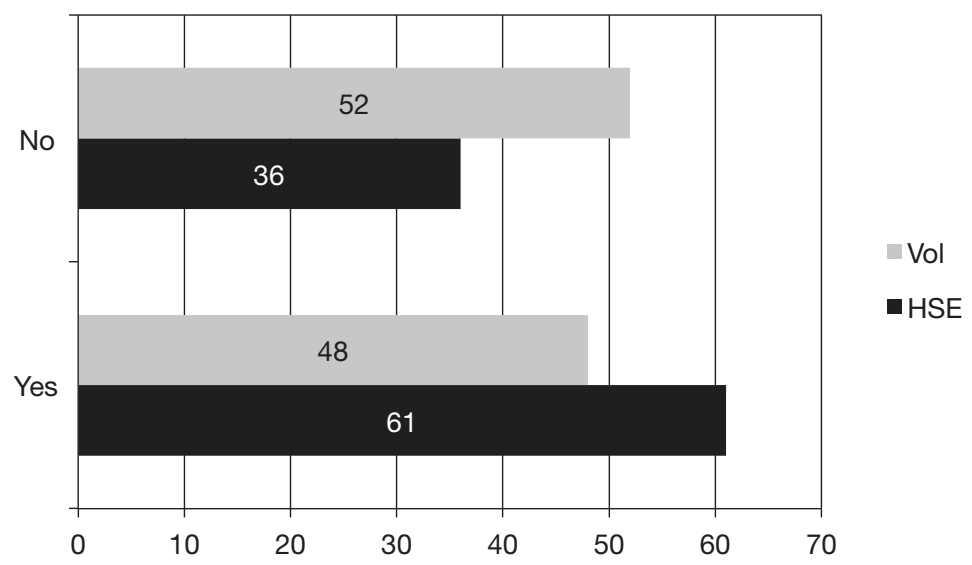


morning for $€ 30$ per hour. Home helps from the voluntary agency were asked the same question relating to working on a Saturday night for $€ 23$ per hour.

A clear majority of respondents from the $\operatorname{HSE}(n=67,60.9$ per cent) said that they would work Saturday night for $€ 30$ per hour, and just under half of employees in the voluntary agency $(n=41,47.7$ per cent) said that they would work for $€ 23$ per hour. The difference between the two groups in frequency in willingness to work this shift is significant $\left[\chi^{2}(1, \mathrm{n}=193)=4.320, \mathrm{p}=0.038\right]$.

\section{Home helps' willingness to work Saturday and Sunday evenings}

Figure 6 shows that over half the respondents from both organisations (HSE $n=50,53$ per cent; voluntary $n=58,58$ per cent) indicated that they would be prepared to work weekend evening hours. No significant difference was found in the frequency of views between the groups $\left.\left[\chi^{2}(1, \mathrm{n}=195)=0.0473, \mathrm{p}=0.492\right)\right]$. This would indicate that home help employees are willing to work these hours for the standard pay rates specified on the questionnaire.

Figure 6: Home helps' willingness to work on Saturday and Sunday evenings (\%)

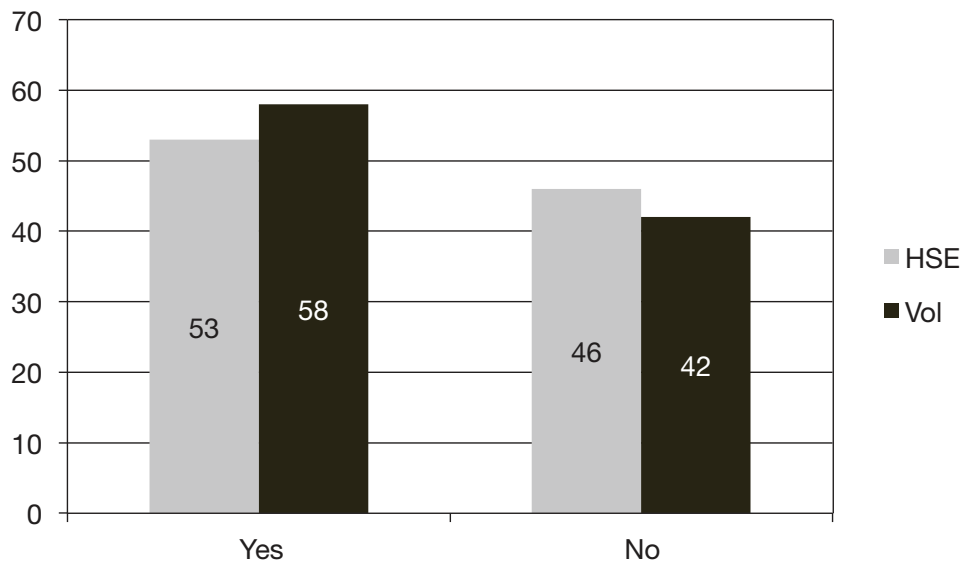

Chester et al. (2014) state that training improves the confidence of home care staff and therefore can directly contribute to the quality of care delivered. According to Heskett (1987), training leads to increased self-esteem among staff and contributes to the personal development of the employee. In the past, insufficient training and a 
lack of support have highlighted the need for better employment conditions to retain employees and to provide a more 'flexible personcentred home care service for older people' (King et al., 2012, p. 366). Home helps from both organisations in this study provide personal care in addition to essential household tasks for the older person who wishes to remain at home. The following result refers to Question 8, which asked the respondents if they would work outside the times of 8 a.m. and 8 p.m. if they could receive more training in care of the older person (Figure 7).

Figure 7: Home helps' willingness to work outside 8 a.m. to 8 p.m. if they received more training in care of the older person (\%)

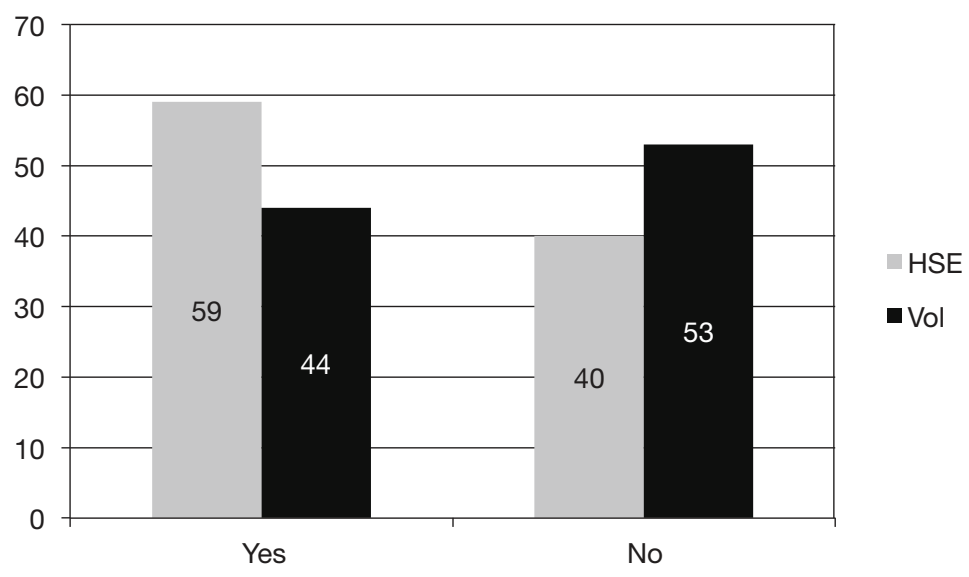

A majority of HSE staff $(n=64,59.3$ per cent) indicated that they would work outside of the specified hours in return for more training, whereas fewer than half of the voluntary agency staff $(n=36,43.9$ per cent) indicated that they would work the hours in return for training. The difference in response frequency between the two groups is significant $\left[\chi^{2}(4, \mathrm{n}=190)=4.409, \mathrm{p}=0.036\right]$.

\section{Duties}

Question 9 in the questionnaire asked home help staff to select one, both or all three of the following tasks that they would perform if they were allocated another fifteen minutes:

- hanging out washing;

- assisting with meal preparation;

- having time to talk to their client. 
As seen in Figure 8, over 50 per cent of HSE home helps indicated at that all three of the tasks could be provided. Almost one-third (30.2 per cent) of HSE respondents and over half (51 per cent) of the respondents in the voluntary agency indicated that they would choose talking to their clients. This suggests that several of the home helps felt that companionship was important for the care recipient, although this feeling was more common among staff working with voluntary agencies. There is a statistically significant difference in the frequency of views between the two groups $\left[\chi^{2}(4, n=189)=13.035, p=0.011\right]$. This was consistent with the theme of companionship that was found in the focus groups with the older people.

Figure 8: Duties that home helps would perform if they were allocated an extra fifteen minutes (\%)

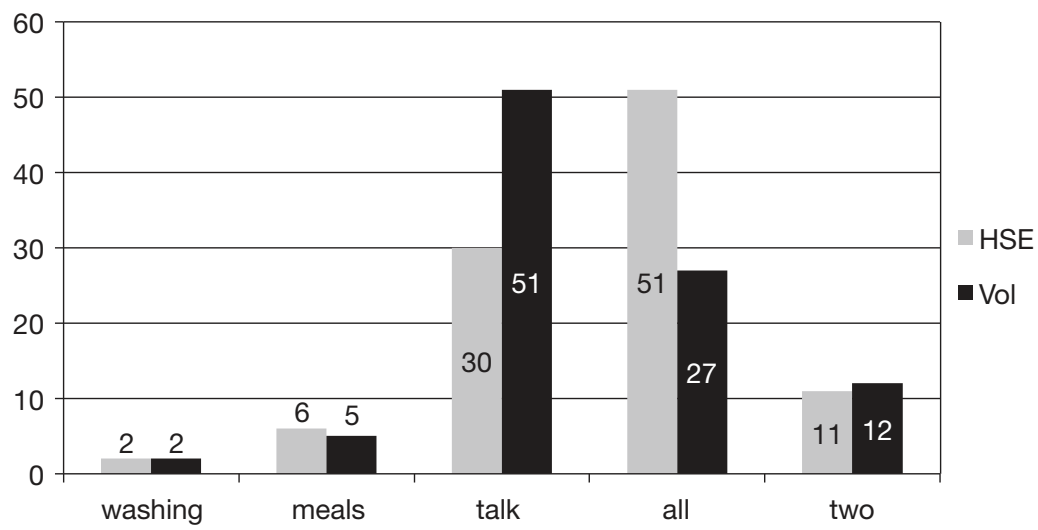

Figure 8 also shows that a very small percentage (HSE $n=2,1.9$ per cent; voluntary $n=2,2.4$ per cent) in both groups identified hanging out washing as a task that could be prioritised. Similarly, regarding meal preparation, both groups had very small numbers identifying the task as a main duty (HSE $n=6,5.7$ per cent; voluntary $n=5,5$ per cent). A much higher percentage of both groups, particularly the voluntary agency, identified talking to the client as a priority (HSE $\mathrm{n}=32,30.2$ per cent; voluntary $\mathrm{n}=44,51$ per cent). However, a number of respondents answered that all of the duties identified could be performed with an extra fifteen minutes (HSE $n=54,50.9$ per cent; voluntary $n=22,26.5$ per cent). A small number of HSE and voluntary agency employees indicated that two of the duties could be undertaken (HSE $n=12,11.3$ per cent; voluntary $n=10,12$ per cent). 
(See the methods section above regarding questionnaire design issue affecting responses to this question.)

Although a high percentage of respondents in the questionnaires indicated that they would not work weekends, there was an increase among both HSE workers and voluntary agency home help staff willing to work the hours when the salary was clearly visible in the second part of the questionnaire. This illustrates the responsiveness of the home help staff to an increase in salary. Data from the quantitative analysis in this study indicated that, although the majority of employees who answered the questionnaire would like to work Monday to Friday, 9 a.m. to 5 p.m., HSE staff were more willing to work outside contracted hours; for example 8 p.m. to midnight midweek or on Sunday evenings.

\section{Incentives to work outside contracted hours}

According to Theobald (2012, p. 279), the need to deliver '24-hour or weekend care' resulted in an increase in part-time working arrangements for care workers in Germany, which has presented employment opportunities but has led to worsening conditions of employment. Literature reviewed for this study identified that the terms and conditions of employment are more favourable in the public sector than in the voluntary sector in the area of home care (Genet et al. 2011; Timonen \& Doyle, 2007). Literature suggests that the increase in private agencies has contributed to low wages and dissatisfaction among workers in home care, which has often resulted in a high turnover of staff and a lack of continuity for the older person. However, private provision of care has also assisted in introducing flexibility in the home care sector regarding time and tasks (Rostgaard, 2012; Theobald, 2012). The low turnover of home help employees in the HSE may be due to home helps feeling valued as part of a large organisation, in addition to enjoying relatively favourable terms and conditions.

Flodgren et al. (2011) carried out a systematic review of thirty-two studies, including randomised controlled trials investigating the effectiveness of financial incentives in healthcare. However, it must be noted that these studies were conducted on health professionals such as doctors, nurses and allied health professionals; care workers were not included in the study. Nonetheless, the findings indicated that financial incentives may influence professional practice. Data from the quantitative analysis in this study indicated that home help employees, particularly in the HSE, are willing to work outside contracted hours - 
for example 8 p.m. to midnight midweek or on Sunday evenings possibly because their rate of pay per hour is higher. Therefore, the possibility of recruiting HSE home help staff in the future to work part-time needs to be considered to allow for a more person-centred home help service.

\section{Conclusion: Towards a more person-centred service}

This study has interrogated aspects of the current model of the Irish home help service by exploring the views of both the care recipients and the home help employees. The findings indicate that the service needs to become more person-centred, and in particular more focused on providing a greater degree of choice and companionship to meet the needs of the older person.

The care recipients spoke about their home helps rushing to do the tasks in the home and not having time to talk to them. Doniol-Shaw \& Lada (2011) argue that there is always discourse between the carer and the care recipient during a home care visit, although the developments in services have often resulted in the carer carrying out specified tasks rather than working with the client. They identified that the task-based model of home help was not designed to meet the care recipients' needs and often resulted in a fragmented service. This approach to home care can result in physical and mental strain on the carer (Doniol-Shaw \& Lada, 2011; Larsson et al., 2013; Taylor \& Donnolly, 2006). Currently, the Irish model of home help provision is determined by the allocated budget and, arguably, it is designed to meet the demands of the service provider, rather than meeting the needs of the care recipient (O'Shea \& Connolly, 2012).

Since 2012, the HSE has placed more emphasis on providing personal care for the older person in the home (HSE, 2011). This has resulted in home helps having to work at a greater intensity while still providing a high level of care. Doyle \& Timonen (2007, p. 331) argued that the home care sector in Ireland was 'more the result of gradual evolution than systematic planning', which still appears to be the case in terms of meeting the demands of the increasing aging population. The literature is consistent with the findings of the qualitative data analysis from this study, where many of the participants in the focus groups spoke about having a home help service of half an hour or less. International best practice suggests that calls of less than half an hour are only recommended as part of the larger $\mathrm{HCP}$, and that if such a call is put in place, the carer should be known to the older person (National Institute for Care and Excellence, 2015). 
The data from both phases of this research have indicated that the care recipient and the employee feel that there is a deficiency in the existing model of home help regarding the time pressure on the employees. The older people in this study had concerns about the home help rushing, and the employees wanted to devote more time to talking with their clients. It is hoped that this information will be used to promote safe practice for employees, and that the task-based care currently provided by the home help is reviewed, to allow a more person-centred service.

Data from the questionnaires in this study could be used for the future recruitment of personnel interested in working in the home help service. Respondents indicated their preference for working weekends or outside contracted hours for pay-related incentives and training. This information could be used in recruiting people for weekend or evening work, which may reduce the amount of care outsourced at the present time.

Rostgaard (2012, p. 249) discusses the introduction of a more flexible home care system in Denmark in 2000, which resulted in the care recipient and the carer having the flexibility to negotiate the tasks performed. This was framed by having a standardised (but flexible) list of services available to the home help and the older person. Although this method allowed for some regulation of services, it also promoted consultation between both the home help and the older person. The National Institute for Care and Excellence guidelines, which provide recommendations for the delivery of home care, incorporating both personal care and practical support to older people, recently recommended that the care recipient be allowed to identify the tasks that they feel can best meet their needs, thus empowering the service user (National Institute for Care and Excellence, 2015, p. 11).

Quality and quantity of communication between care recipients and care management/planners also emerged as key issues in this study. According to Frampton \& Charmel (2009), quality care has communication and human relationships at its core. In the focus groups carried out in this study, participants spoke about the need for communication from the managers of the service, to keep them informed of developments in the service they received. They felt that sometimes the lack of communication created a risk to their safety, if they did not know the replacement home help.

Presently the home help model in Ireland is task-based and does not facilitate the carer working with the older person to promote independence in the home. Models such as restorative homecare in 
New Zealand and reablement programs in the UK have attempted to allow the service user to relearn skills that they need in order to remain living at home. This person-centred approach to home care allows the recipient to regain their confidence at home by developing their skills to live independently (Glendinning et al., 2010; King et al., 2012). Models such as these could provide lessons for the development of the Irish home help service, and provide a promising avenue for reforming home care services in a direction that better serves the needs of the care recipients.

\section{References}

Barello, S., Graffigna, G., \& Vegni, E. (2012). Patient engagement as emerging challenge for healthcare services: Mapping the literature. Nursing Research and Practice, 2012, 1-7.

Boeckxstaens, P., \& De Graaf, P. (2011). Primary care and care for the older persons: Position paper of the European forum for primary care. Quality in Primary Care, 19, 369-89.

Breitholtz, A., Snellman, I., \& Fagerberg, I. (2013). Living with uncertainty: Older persons' lived experience of making independent decisions over time. Nursing Research and Practice, 2013, 1-8.

Bryman, A. (2004). Social research methods (2nd ed.). New York: Oxford University Press.

Chester, H., Hughes, J., \& Challis, D. (2014). Commissioning social care for older people: Influencing the quality of direct care. Ageing and Society, 34 (6), 930-50.

Department of Health. (1972). Home help service, circular 11/72. Dublin: The Stationery Office.

Department of Health and Children. (2001). Primary care, a new direction. Dublin: The Stationery Office.

Department of Health and Children. (2005). Home help service, circular 11/72. Retrieved from http://www.dohc.ie/press/releases/2005/20051208.html [29 March 2013].

Department of Health and Children. (2009). Evaluation of home care packages. Dublin: The Stationery Office.

Department of Health and Children. (2012). Future health: A strategy framework for reform of the health service 2012-2015. Dublin: Department of Health and Children.

Doniol-Shaw, G., \& Lada, E. (2011). Work schedules of home care workers for the elderly in France: Fragmented work, deteriorating quality of care, detrimental health impact. IOS Press, 40, 531-46.

Doyle, M., \& Timonen, V. (2007). From the workhouse to the home: Evolution of care policy for older people in Ireland. International Journal of Sociology and Social Policy, 28, 76-89. 
Dybbroe, B. (2008). Crisis of care in a learning perspective. In S. Wrede, L. Henriksson, H. Host, S. Johansson \& B. Dybbroe (Eds), Care work in crisis: Reclaiming the Nordic ethos of care (pp. 41-8). Lund: Student Literature.

Flodgren, G., Eccles, M. P., Shepperd, S., Scott, A., Parmelli, E., \& Beyer, F. R. (2011). An overview of reviews evaluating the effectiveness of financial incentives in changing healthcare professional behaviours and patient outcomes. The Cochrane Collaboration, 7, 1-94.

Frampton, S., \& Charmel, P. (2009) Putting patients first: Best practices in patient centred care (2nd ed.). San Francisco: Jossey-Bass.

Genet, N., Boerma, W. G. W., Kringos, D. S., Bourman, A., Francke, A. L., Fagerstrom, C., Melchhiorre, M. G., Greco, C., \& Develle, W. (2011). Home care in Europe: A systematic literature review. BMC Health Services Research, 11 (27), 1-14.

Glaser, B., \& Strauss, A. (1967). The discovery of grounded theory: Strategies for Qualitative research. Aldine: Atherton.

Glendinning, C., Jones, K., Baxter, K., Rabiee, P., Curtis, L., Wilde, A., Arksey, H., \& Forder, F. (2010). Home care re-ablement services: Investigating the longer-term impacts (prospective longitudinal study) [Working paper no. DHR 2438]. York: University of York.

Gruman, J., Holmes Rovner, M., French, M., Jeffress, D., Sofar, S., Shaller, D., \& Prage, D. (2010). From patient education to patient engagement: Implications for the field of patient education. Patient Education and Counselling, 78 (3), 350-6.

Heskett, L. (1987). Lessons in the private sector. Harvard Business Review, 65 (2), 118-26.

HIQA. (2012). National standards for better healthcare. Dublin: HIQA.

Howes, C. (2008). Love, money, or flexibility. What motivates people to work in consumer-directed home care? The Gerontologist, 48 (1), 46-59.

HSE. (2011). National service plan 2012. Retrieved from http://www.hse.ie/ eng/services/Publications/corporate/nspexecutivesummary2012.pdf [2 February 2014].

HSE. (2014). National service plan 2015. Dublin: HSE.

HSE. (2015). Office of the Head of Operations \& Service Improvement Services for Older People. Unpublished Internal Document, Cork.

INMO. (2015). Community nursing issues 20.10.2015. Retrieved from http://www.inmo.ie/Home/Index/7352/12538 [22 July 2016].

Karlsson, S., Edberg, A. K., Jakobsson, U., \& Hallberg, R. (2013). Care satisfaction among older people receiving public care and service at home or in special accommodation. Journal of Clinical Nursing, 22, 318-30.

King, A., Parsons, M., Robinson, E., \& Jorgensen, D. (2012). Assessing the impact of a restorative home care service in New Zealand. Health and social care in the community, 20 (4), 365-74.

Labour Court. (2013). HSE v SIPTU, IMPACT, CD/12/527 Home helps. Dublin: Labour Court. 
Larsson, A., Karlqvist, L., Westerberg, M., \& Gard, G. (2013). Perceptions of health and risk management among home care workers in Sweden. Physical Therapy Reviews, 18 (5), 336-43.

Lundstrom, F., \& McKeown, K. (1994). Home help service for the elderly people in Ireland. Dublin: National Council for the Elderly.

National Council on Ageing and Older People and the Department of Health and Children. (1998). The future organisation of the home help service in Ireland, Report no 53. Dublin: National Council of Ageing and Older People.

National Institute for Care and Excellence. (2015). Home care: Delivering personal care and practical support to older people living in their own homes, NICE guidelines. Retrieved from http://nice.org.uk/guidance/ng21 [24 September 2015].

Normand, C. (2012). The healthcare system in Ireland: Controlling growth in expenditure and making the best use of resources. In T. Callan (2011), Budget perspectives [Research series no. 22]. Dublin: ERSI.

O'Shea, E., \& Connolly, S. (2012). Reforming health production in Ireland. The world economy, 35 (10), 1,359-71.

Rostgaard, T. (2012). Quality reforms in Danish home care - balancing between standardisation and individualisation. Health and Social Care in the Community, 20 (3), 247-54.

Skaperdas, I., Lavdanti, M., Dimitriadou, A., Psychogiou, M., Sgantzos, M., \& Krepia,V. (2010). Satisfaction from the 'Help at Home' programme in a prefecture of central Greece. International Journal of Nursing Practice, 16, 342-51.

Stolt, R., \& Winbauld, U. (2009). Mechanisms behind privatization: A case study of private growth in Swedish elderly care. Social Science Med, 68, 903-11.

Strauss, A., \& Corbin, J. M. (1990). Basics of qualitative research: Grounded theory and procedures and techniques. Newbury Park, California: Sage.

Taylor, B., \& Donnolly, M. (2006). Risks to home care workers: Professional perspectives. Health Risk and Society, 8, 239-56.

Theobald, H. (2012). Home-based care provision within the German welfare mix. Health and Social Care in the Community, 20 (3), 274-82.

Timonen, V., \& Doyle, M. (2007). Worlds apart? Public, private and nonprofit sector, providers of domiciliary care for older persons in Ireland. Journal of Aging Studies, 21 (3), 255-65.

Timonen, V., \& Doyle, M. (2008). Breaking the mould: New trajectories in the domiciliary care of older people in Ireland. International Journal of Social Welfare, 17, 324-32.

Timonen, V., Doyle, M., \& O’ Dwyer, C. (2012). Expanded but not regulated: Ambiguity in home care policy in Ireland. Health and Social Care, 20 (3), 310-18. 